\title{
A prevalence survey of every-day activities in pregnancy
}

Samantha J Lain ${ }^{1 *}$, Jane B Ford', Ruth M Hadfield ${ }^{1}$, Christine L Roberts ${ }^{1,2}$

\begin{abstract}
Background: Research into the effects of common activities during pregnancy is sparse and often contradictory. To examine whether common activities are an acute trigger of pregnancy complications the prevalence of these activities are necessary to determine sample size estimates. The aim of this study is to ascertain the prevalence of selected activities in any seven day period during pregnancy.

Methods: The study was conducted in the antenatal clinic of a teaching hospital with tertiary obstetric and neonatal care in Sydney, Australia between August 2008 and April 2009. Women who were at least 20 weeks pregnant and able to read English completed a questionnaire to assess whether they had performed a list of activities in the seven days prior to survey completion. Results were analysed using frequency tabulations, contingency table analyses and chi square tests.
\end{abstract}

Results: A total of 766 surveys were completed, 29 surveys were excluded as the women completing them were less than 20 weeks pregnant, while 161 women completed the survey more than once. Ninety seven per cent of women completed the survey when approached for the first time, while $87 \%$ completed the survey when approached a subsequent time. In the week prior to completing the survey $82.6 \%$ of women had consumed a caffeinated beverage, $42.1 \%$ had had sexual intercourse, 32.7\% had lifted something over 12 kilograms, $21.4 \%$ had consumed alcohol and $6.4 \%$ had performed vigorous exercise. The weekly prevalence of heavy lifting was higher for multiparous women compared to nulliparous women.

Conclusions: The results of this study can be used to inform future research into activities as acute triggers of pregnancy complications.

\section{Background}

Women have many concerns about the safety of performing otherwise everyday activities during pregnancy. Pregnant women seek information about air travel, sexual intercourse and exercise during pregnancy[1], while antenatal care providers may also need to confirm or refute pregnancy 'old wives' tales', such as eating spicy food to induce labour[2]. However research into the effects of these and other common activities during pregnancy is sparse and often contradictory[3-10].

To perform high quality research into the effects of these activities in pregnant women, each study needs a sample size large enough to demonstrate differences between groups of women. To calculate the sample size for a case-control or case-crossover study requires the

\footnotetext{
* Correspondence: samantha.lain@sydney.edu.au

${ }^{1}$ Perinatal Research, Kolling Institute of Medical Research, University of Sydney, St Leonards, NSW, Australia
}

(C) 2010 Lain et al; licensee BioMed Central Ltd. This is an Open Access article distributed under the terms of the Creative Commons Attribution License (http://creativecommons.org/licenses/by/2.0), which permits unrestricted use, distribution, and reproduction in any medium, provided the original work is properly cited. prevalence of these activities during pregnancy. As most activities are transient in nature, the timing of these activities may be important as a possible acute trigger of pregnancy complications such as preterm birth, placental abruption, premature spontaneous rupture of membranes and preeclampsia. Pregnant women have been asked to report the frequency of performing every-day activities during specific trimesters[4,9,11-13] or any time during pregnancy[3,14-16]; however, to investigate these activities as acute triggers it is important to know their prevalence in a smaller window of time. The aim of this study is to ascertain the prevalence of selected activities in any seven day period during pregnancy.

\section{Methods}

The study was conducted in the antenatal clinic of a teaching hospital with tertiary obstetric and neonatal care in Sydney, Australia between August 2008 and 
April 2009. Women who were at least 20 weeks pregnant and were able to complete the questionnaire in English were eligible. As the questionnaire sought information about events in the seven days prior to its completion, women were eligible to complete the survey more than once, providing there was at least fourteen days between each questionnaire.

Eligible women were approached by a researcher in the antenatal clinic waiting area and given written and verbal information about the study. The researcher was present in the antenatal clinic from Monday to Friday ensuring women receiving care from different health providers were recruited (49\% of women were visiting General Practitioners, $40 \%$ were visiting a midwife and $11 \%$ were in a high-risk clinic). Women who consented to be in the study completed the survey while waiting for their antenatal appointment. The questionnaire was developed from a review of literature and discussion with clinical staff of possible acute triggers for conditions in pregnancy. Questionnaire development included pilot testing on fifteen women attending antenatal appointments and refinement. Minimal changes were required to the survey following pilot testing so it was decided that re-piloting was not necessary. The questionnaire took 3 to 5 minutes to complete and asked women about demographic characteristics and whether they had engaged in a list of activities in the seven days prior to completing the questionnaire.

Survey data were analysed using frequency tabulations and contingency table analyses using SAS, version 9.1 (SAS Institute, Cary NC, USA). Stratified analysis, using chi square tests, examined the impact of gestational age (20-28 weeks, 29-34 weeks, and 35 weeks or more), parity (first pregnancy compared to second or subsequent pregnancy), maternal age (less than 25 years, 25 to 34 years, and 35 years or more) and maternal education (university degree compared to no university degree) on prevalence of activities. Stratified analyses were performed based on number of women who completed the survey compared to total number of surveys to examine the effect of clustering of activities amongst women who completed the survey more than once. This study was approved by the Northern Sydney and Central Coast Human Research Ethics Committee.

\section{Results}

Ninety seven per cent of the women approached the first time to participate in the study consented. When women were approached to complete the survey for a subsequent time $87 \%$ consented. A total of 766 surveys were completed, 29 surveys were excluded as the women completing them were less than 20 weeks pregnant, while 161 women completed the survey more than once. The majority of the women that completed the survey were over 30 years of age, had a University degree, and were having their first baby (Table 1).

The weekly prevalence rates for recent activities, calculated from all surveys completed, are outlined in Table 2. The most prevalent activity in the week prior to completing the survey was drinking caffeinated beverages, this included coffee, tea or cola drinks. The activities occurring most infrequently were taking medication for depression (2.4\%) and plane travel (4.5\%). The prevalence rates of activities performed by individual women did not differ significantly to prevalence rates calculated from all surveys (see Table 2).

\section{Prevalence of activities stratified by gestational age}

The prevalence rates of most activities did not vary significantly with gestation. However, performing vigorous exercise in the seven days prior to the survey was most prevalent amongst women 29 to 34 weeks pregnant, $11.1 \%$ compared to $5.8 \%$ and $4.3 \%$ for women 20 to 28 weeks pregnant and those over 34 weeks pregnant respectively $(\mathrm{p}=0.01)$. The prevalence of an internal examination increased with gestational age (3.3\%, 5.2\%, $8.6 \% ; \mathrm{p}=0.03)$ while the prevalence of plane travel decreased with gestation $(6.6 \%, 5.2 \%, 2.5 \%$; $\mathrm{p}=0.05)$.

\section{Prevalence of activities stratified by parity}

Compared to women who were pregnant for a second or subsequent time, fewer women who were pregnant for the first time consumed caffeinated drinks $(76.9 \%$ vs $88.6 \%$, p < $0.001)$, or lifted something over 12 kilograms (8.2\% vs $58.1 \%$, $\mathrm{p}<0.001)$ in the past seven days, while more women having their first baby had had an internal examination (8.2\% vs $3.9 \%, p=0.01)$. Although not a statistically significant difference $(\mathrm{p}=0.06)$, more multiparous women had consumed alcohol in the seven days prior to completing the survey than women pregnant for the first time (24.3\% vs $18.6 \%)$.

\section{Prevalence of activities stratified by maternal age}

The prevalence of lifting something over 12 kilograms in the week prior to survey completion increased with maternal age $(\mathrm{p}<0.001)$ while the prevalence of an internal/vaginal examination decreased with age $(\mathrm{p}=$ 0.01 ). However when these analyses were stratified by parity, there was no longer a significant difference between age groups. Compared to women aged 25 years and older, the prevalence rate for taking medication for depression was higher for women aged less than 25 years $(7.3 \%$ vs $1.9 \%, \mathrm{p}=0.01)$. This difference remained for multiparous women after stratified analysis by parity.

\section{Prevalence of activities stratified by maternal education}

The prevalence of two activities differed significantly by maternal education. Women who had a University degree had higher prevalence rates of lifting something 
Table 1 Distribution of demographic characteristics in the study population

\begin{tabular}{|c|c|c|}
\hline & $\begin{array}{l}\text { Women who completed survey for } \\
\qquad \text { first time } \\
N=576\end{array}$ & $\begin{array}{l}\text { Women who completed survey second or } \\
\text { subsequent time } \\
\qquad N=161\end{array}$ \\
\hline Age (years) & $\mathrm{N}(\%)$ & $\mathrm{N}(\%)$ \\
\hline$<25$ & $45(7.9)$ & $10(6.3)$ \\
\hline $25-29$ & $119(20.8)$ & $24(15.0)$ \\
\hline $30-34$ & 221 (38.6) & $65(40.6)$ \\
\hline$\geq 35$ & $187(32.7)$ & $61(38.1)$ \\
\hline \multicolumn{3}{|l|}{ Gestation (weeks) } \\
\hline $20-28$ & $217(37.7)$ & $24(14.9)$ \\
\hline $29-34$ & $134(23.3)$ & $38(23.6)$ \\
\hline $35-40$ & $225(39.2)$ & $99(61.4)$ \\
\hline \multicolumn{3}{|l|}{ Plurality } \\
\hline Singleton & $556(96.7)$ & $149(92.5)$ \\
\hline Twins/Triplets & $19(3.3)$ & $12(7.5)$ \\
\hline \multicolumn{3}{|l|}{ Number of previous pregnancies } \\
\hline 0 & $294(51.1)$ & $82(50.9)$ \\
\hline 1 or more & $281(48.9)$ & $79(49.1)$ \\
\hline \multicolumn{3}{|l|}{ Highest level of education completed } \\
\hline Secondary school or below & $73(12.7)$ & $14(8.7)$ \\
\hline TAFE/Diploma/Certificate & $183(31.9)$ & $83(26.7)$ \\
\hline University degree & $318(55.4)$ & $104(64.6)$ \\
\hline \multicolumn{3}{|l|}{$\begin{array}{l}\text { Medical conditions (pre-existing or pregnancy } \\
\text { related) }\end{array}$} \\
\hline Asthma & $50(8.7)$ & $18(11.2)$ \\
\hline High blood pressure & $21(3.6)$ & $6(3.7)$ \\
\hline Diabetes & $37(6.4)$ & $14(8.7)$ \\
\hline Other & $24(4.2)$ & $7(4.4)$ \\
\hline \multicolumn{3}{|l|}{ Smoking status } \\
\hline Smoked cigarettes prior to being pregnant & $85(14.8)$ & $26(16.2)$ \\
\hline Smoked cigarettes during pregnancy & $24(4.2)$ & $5(3.1)$ \\
\hline
\end{tabular}

Table 2 The weekly prevalence rate, per 100 surveys, of activities/events reported in surveys

\begin{tabular}{|c|c|c|}
\hline & $\begin{array}{l}\text { Prevalence }(95 \% \mathrm{Cl}) \text { on all surveys } \\
\text { completed }\end{array}$ & $\begin{array}{c}\text { Prevalence }(95 \% \mathrm{Cl}) \text { on women who completed survey } \\
\text { once }\end{array}$ \\
\hline Consumed caffeinated drinks & $82.6(79.9-85.4)$ & $82.1(78.9-85.2)$ \\
\hline Eaten hot and spicy food & $47.2(43.5-50.8)$ & $45.3(41.2-49.4)$ \\
\hline Had sexual intercourse & $42.1(38.5-45.6)$ & $43.1(39.1-47.2)$ \\
\hline $\begin{array}{l}\text { Lifted anything of more than } 12 \\
\text { kilograms }\end{array}$ & $32.7(29.3-36.1)$ & $32.2(28.3-36.0)$ \\
\hline Consumed alcohol & $21.4(18.4-24.4)$ & $20.6(17.3-23.9)$ \\
\hline Performed vigorous physical exercise & $6.4(4.6-8.1)$ & $6.6(4.6-8.6)$ \\
\hline Had an internal/vaginal examination & $6.1(4.4-7.8)$ & $5.7(3.8-7.6)$ \\
\hline Onset of an infection & $5.0(3.4-6.6)$ & $4.7(3.1-6.6)$ \\
\hline Travelled in an aeroplane & $4.5(3.0-6.0)$ & $4.5(2.8-6.2)$ \\
\hline Taken medication for depression & $2.4(1.3-3.6)$ & $2.6(1.3-3.9)$ \\
\hline
\end{tabular}

12 kilograms or more $(\mathrm{p}=0.004)$, although when stratified for parity this difference only remained for multiparous women. Women without University degrees had a higher prevalence of taking medication for depression ( $4.8 \%$ vs $0.7 \%, \mathrm{p}>0.001)$, this was significant for both primiparous and multiparous women.

\section{Discussion}

This is the first study to look at the prevalence of activities or events in a seven day window in pregnant women. However there are a number of studies that report the prevalence of select activities during specific trimesters $[3,9,11,12]$ or at any time during pregnancy 
$[3,14,15]$. Activities that may be performed regularly during pregnancy and have rates that do not differ with gestational age can be compared to other rates calculated during the whole pregnancy. Prevalence rates similar to our study were recorded for performing vigorous exercise ( $8 \%$ in second trimester)[9], and having sexual intercourse $(44 \%$ and $45 \%)[4,6]$. One study reported a higher rate of physical activity (49\% once or more a week) and a lower rate of sexual intercourse (24\%) this could be due to the population of nulliparous, younger women surveyed[11].

Reported rates that differed from the findings from this survey included having medication for depression dispensed, $3.8 \%$ during second trimester to $4.1 \%$ in the third trimester [13]. Our rate (2.4\%) may be lower as we asked if depression medication had been taken in the past week. Another explanation for the difference in results may be the study population. The population in our study is much older than the population reported in this study, with only $7.4 \%$ of surveyed women under the age of 25 years in our study compared to $15 \%$. We found that the prevalence of taking medication for depression was significantly higher (7.3\%) for women aged less than 25 years. Reported prevalence rates for coffee consumption during pregnancy range from $43 \%$ [6] to $57 \%[16]$ however the higher prevalence rate of $83 \%$ in our study included the consumption of tea and cola drinks. Our finding of prevalence rates of $21 \%$ for alcohol consumption during pregnancy were lower than findings from Denmark (44.7\%) [17] and Canada (31.2\%) [16]. Although we did not ask about quantities of alcohol consumed we believe the majority of women drinking alcohol have only consumed small quantities as in the Canadian study $18 \%$ of pregnant women had consumed only one or two drinks per week[16]. Interestingly, at the end of 2007, prior to this study commencing, the National Health and Medical Research Council in Australia publicly released a guideline advising women that it is safest to abstain from alcohol consumption whilst pregnant[18].

For activities that occur less frequently during pregnancy it is necessary to estimate weekly rates for comparison to studies that have collected data over varying lengths of time during pregnancy. Another study found a weekly rate of plane travel for women at least 20 weeks pregnant of approximately 3.3\%[6]. Although similar to our finding of $4.5 \%(3.0 \%-6.0 \%)$, the population of women attending antenatal clinics at this hospital is of average to advantaged socioeconomic status and therefore may travel by air more than the general population.

We found that for women that had previously been pregnant, the prevalence of lifting something 12 kilograms or more was higher. Infants aged 12 months or more may weigh 12 kilograms[19] and this may also explain the different prevalence rates of heavy lifting between different maternal age groups and education levels. Older women are more likely to have been pregnant before and are also more likely to have a University degree.

A limitation of this study is the use of self reported data which may be affected by recall bias. Mothers' reports of events during pregnancy and labour are generally good[20,21], and are more reliable if less time has elapsed from the event of interest[22]. The seven day period of recall in our study is short and should minimise recall bias. A further limitation of this study is that the study population is older than the general population of pregnant women in Australia[23], is highly educated and speaks English impacting the generalisability of the results, especially for prevalence of activities that differ with maternal age, education or socioeconomic status. Women who completed the survey more than once were more likely to have more complicated pregnancies and increased gestational age as these women attended the antenatal clinic more often.

\section{Conclusions}

This survey is the first study to estimate the weekly prevalence of a number of activities and events in a population of pregnant women. Further research is necessary to investigate whether any of these activities are acute triggers of pregnancy complications. The results of this study can be used to inform such future research or be a guide to clinicians on the prevalence of possibly risky activities amongst different groups of pregnant women.

\section{Acknowledgements}

We wish to acknowledge the help of research midwives Kristen Rickard, Jill Milligan and Jocelyn Sedgley with administering surveys in the antenatal clinic. Samantha Lain is supported by a National Health and Medical Research Council (NHMRC) Post-graduate Scholarship. Christine Roberts is supported by a National Health and Medical Research Council (NHMRC) Senior Research Fellowship. Ruth Hadfield is supported by an NHMRC Australian Research Training Fellowship. Jane Ford is supported by an NHMRC Capacity Building Grant in Population Health Research.

\section{Author details}

${ }^{1}$ Perinatal Research, Kolling Institute of Medical Research, University of Sydney, St Leonards, NSW, Australia. ²Department of Obstetrics and Gynaecology, Royal North Shore Hospital, St Leonards, NSW, Australia.

\section{Authors' contributions}

SJL designed and administered the survey, analysed data and drafted manuscript. CLR and JBF developed the study and helped design the survey. $\mathrm{CLR}$ and $\mathrm{RMH}$ contributed to data analysis and interpretation. All authors edited the manuscript and gave final approval of the version to be published.

\section{Competing interests}

The authors declare that they have no competing interests.

Received: 24 February 2010 Accepted: 4 August 2010

Published: 4 August 2010 


\section{References}

1. Freda MC, Andersen HF, Damus K, Merkatz IR: What pregnant women want to know: a comparison of client and provider perceptions. J Obstet Gynecol Neonatal Nurs 1993, 22(3):237-244.

2. Schaffir J: Survey of folk beliefs about induction of labor. Birth 2002, 29(1):47-51.

3. Misra DP, Strobino DM, Stashinko EE, Nagey DA, Nanda J: Effects of physical activity on preterm birth. Am J Epidemiol 1998, 147(7):628-635.

4. Tan PC, Andi A, Azmi N, Noraihan MN: Effect of coitus at term on length of gestation, induction of labor, and mode of delivery. Obstet Gynecol 2006, 108(1):134-140.

5. Pompeii LA, Savitz DA, Evenson KR, Rogers B, McMahon M: Physical exertion at work and the risk of preterm delivery and small-forgestational-age birth. Obstet Gynecol 2005, 106(6):1279-1288.

6. Petridou E, Salvanos H, Skalkidou A, Dessypris N, Moustaki M, Trichopoulos D: Are there common triggers of preterm deliveries? Bjog 2001, 108(6):598-604.

7. Marcoux S, Brisson J, Fabia J: The effect of leisure time physical activity on the risk of pre- eclampsia and gestational hypertension. J Epidemiol Community Health 1989, 43(2):147-152.

8. Kurki T, Ylikorkala O: Coitus during pregnancy is not related to bacterial vaginosis or preterm birth. Am J Obstet Gynecol 1993, 169(5):1130-1134

9. Evenson KR, Siega-Riz AM, Savitz DA, Leiferman JA, Thorp JM: Vigorous leisure activity and pregnancy outcome. Epidemiology 2002, 13(6):653-659.

10. Sayle AE, Savitz DA, Thorp JM, Hertz-Picciotto I, Wilcox AJ: Sexual activity during late pregnancy and risk of preterm delivery. Obstet Gynecol 2001, 97(2):283-289.

11. Fox NS, Gelber SE, Chasen ST: Physical and sexual activity during pregnancy and near delivery. J Womens Health (Larchmt) 2008, 17(9):1431-1435.

12. Schmidt MD, Pekow P, Freedson PS, Markenson G, Chasan-Taber L: Physical activity patterns during pregnancy in a diverse population of women. $J$ Womens Health (Larchmt) 2006, 15(8):909-918.

13. Andrade SE, Raebel MA, Brown J, Lane K, Livingston J, Boudreau D, Rolnick SJ, Roblin D, Smith DH, Willy ME, et al: Use of antidepressant medications during pregnancy: a multisite study. Am J Obstet Gynecol 2008, 198(2):194, e191-195

14. Ahlborg G, Bodin L, Hogstedt C: Heavy lifting during pregnancy-a hazard to the fetus? A prospective study. Int J Epidemiol 1990, 19(1):90-97.

15. Freeman M, Ghidini A, Spong C, Tchabo N, Bannon P, Pezzullo J: Does air travel affect pregnancy outcome? Arch Gynecol Obstet 2004, 269(4):274-2777.

16. McDonald AD, Armstrong BG, Sloan M: Cigarette, alcohol, and coffee consumption and prematurity. Am J Public Health 1992, 82(1):87-90.

17. Juhl M, Andersen PK, Olsen J, Madsen M, Jorgensen T, Nohr EA Andersen AM: Physical exercise during pregnancy and the risk of preterm birth: a study within the Danish National Birth Cohort. Am J Epidemiol 2008, 167(7):859-866.

18. National Health and Medical Research Council: Australian Guidelines to reduce health risks from drinking alcohol. Canberra: Commonwealth of Australia 2009.

19. National Center for Chronic Disease Prevention and Health Promotion: CDC Growth Charts - United States. 2000 [http://www.cdc.gov/growthcharts/ clinical_charts.htm\#Set1].

20. Githens PB, Glass CA, Sloan FA, Entman SS: Maternal recall and medical records: an examination of events during pregnancy, childbirth, and early infancy. Birth 1993, 20(3):136-141.

21. Troude P, L'Helias LF, Raison-Boulley AM, Castel C, Pichon C, Bouyer J, de La Rochebrochard E: Perinatal factors reported by mothers: do they agree with medical records? Eur J Epidemiol 2008, 23(8):557-564

22. Elkadry E, Kenton $K$, White $P$, Creech $S$, Brubaker L: Do mothers remember key events during labor? Am J Obstet Gynecol 2003, 189(1):195-200.

23. Laws P, Hilder L: Australia's mothers and babies 2006. Perinatal statistics series no 22 AlHW National Perinatal Statistics Unit 2008.

\section{Pre-publication history}

The pre-publication history for this paper can be accessed here: http://www.biomedcentral.com/1471-2393/10/41/prepub

\section{doi:10.1186/1471-2393-10-41}

Cite this article as: Lain et al: A prevalence survey of every-day activities in pregnancy. BMC Pregnancy and Childbirth 2010 10:41.

\section{Submit your next manuscript to BioMed Central and take full advantage of:}

- Convenient online submission

- Thorough peer review

- No space constraints or color figure charges

- Immediate publication on acceptance

- Inclusion in PubMed, CAS, Scopus and Google Scholar

- Research which is freely available for redistribution 